\title{
Acute effects on brain cholecystokinin-like concentration and anxiety-like behaviour in the female rat upon a single injection of $17 \beta$ - estradiol
}

Lovisa Holm, Wen Liang, Annika Thorsell and Susanne Hilke

\author{
Linköping University Post Print
}

\section{Tweet}

N.B.: When citing this work, cite the original article.

Original Publication:

Lovisa Holm, Wen Liang, Annika Thorsell and Susanne Hilke, Acute effects on brain cholecystokinin-like concentration and anxiety-like behaviour in the female rat upon a single injection of 17ß-estradiol, 2014, Pharmacology, Biochemistry and Behavior, (122), , 222-227. http://dx.doi.org/10.1016/j.pbb.2014.04.004

Copyright: Elsevier http://www.elsevier.com/

Postprint available at: Linköping University Electronic Press http://urn.kb.se/resolve?urn=urn:nbn:se:liu:diva-106089 


\title{
Acute effects on brain cholecystokinin-like concentration and anxiety-like behaviour in the female rat upon a single injection of $17 \beta$-estradiol
}

\author{
Lovisa Holm ${ }^{1}$ Wen Liang ${ }^{2}$ Annika Thorsell ${ }^{1}$ Susanne Hilke ${ }^{3 *}$ \\ ${ }^{1}$ Department of Clinical and Experimental Medicine, Division of Cell Biology, Faculty of \\ Health Sciences, Linköping University, SE-581 85 Linköping, Sweden \\ ${ }^{2}$ TNO Metabolic Health Research, Leiden, Netherland \\ ${ }^{3}$ Department of Clinical Chemistry, Department of Clinical and Experimental Medicine, \\ Faculty of Health Sciences, Linköping University, SE-581 85 Linköping, Sweden \\ *Corresponding author \\ Susanne Hilke, $\mathrm{PhD}$ \\ Department of Clinical and Experimental Medicine (IKE), \\ Division of Clinical Chemistry \\ Linköping University \\ 58185 Linköping, Sweden \\ Email; susanne.hilke@liu.se \\ Phone; +46-10-1031979
}

Running title: $17 \beta$-estradiol influences anxiety-like behaviour and the levels of

cholecystokinin-like immunoreactivity in the female rat brain

Keywords: Cholecystokinin, anxiety, estrogen 


\section{Abstract}

Background: The neuropeptide cholecystokinin (CCK) has been implicated in the neurobiology of anxiety and panic disorders, as well as in dopamine-related behaviours. Anxiety and panic-disorders are twice as common in females compared to males, but studies of females are rare, although increasing in number. Limited studies have found that CCK fluctuates in limbic regions during the estrous cycle, and that CCK and its receptors are sensitive to estrogen. Aim/Purpose: The aim of the present work was to study acute effects of $17 \beta$-estradiol on anxiety-like behaviour and effects on CCK-like immunoreactivity (LI) in the female rat brain (amygdala, hippocampus, nucleus accumbens, and cingulate cortex).

Methods: Four groups of female Sprague-Dawley rats were used: ovariectomized, ovariectomized $+17 \beta$-estradiol -replacement, sham, and sham $+17 \beta$-estradiol -replacement. The effect of $17 \beta$-estradiol -replacement on anxiety-related behaviour was measured in all animals on the elevated plus maze $2-24 \mathrm{hr}$ after injection. CCK-LI concentration was measured in punch biopsies by means of radioimmunoassay.

Results: $17 \beta$-estradiol decreased anxiety-like behaviour 2 hours after administration in ovariectomized and sham-operated animals, as demonstrated by increased exploration of the open arms compared to respective sesame oil-treated controls. This effect was not present when testing occurred $24 \mathrm{hr}$ post-treatment. The rapid behavioural effect of $17 \beta$-estradiol was accompanied by changes in CCK-LI concentrations in regions of the limbic system including cingulate cortex, hippocampus, amygdala and nucleus accumbens.

Conclusion: Although the interpretation of these data requires caution since the data were collected from two different experiments, our results suggest that estrogen-induced anxiolytic effects may be associated with changes of the CCK-system in brain regions controlling anxiety-like behaviour. 


\section{Introduction}

Cholecystokinin (CCK) is involved in the neurobiology of anxiety and panic disorders in both rodents and humans (Karkanias et al. , 1989, Rotzinger et al. , 2010), as well as in dopaminerelated behaviours (Hökfelt et al. , 1980) indicating that CCK plays a role in reward-related behaviour, motivation and addiction, (Lu et al. , 2002, Mitchell et al. , 2006, Pommier et al. , 2002). CCK is highly abundant in the meso-limbic system, e.g. cortex, amygdala, hippocampus and striatum (Hökfelt et al., 1980, Larsson and Rehfeld, 1979, Micevych et al. , 1987, Vanderhaeghen et al. , 1980). Anxiety and panic-disorders are twice as common in females as in males, and sex-differences in the dopamine system and dopamine-related behaviours such as addiction have been reported (Becker, 1999). However, there are few if any studies that have satisfactorily addressed the involvement of CCK in these diseases in females.

CCK acts through the G-coupled CCK receptor 1 (CCK1-R) and CCK 2 receptor (CCK2-R, (IU-PHAR Classification Monograph, http://www.iuphar-db.org) (Beinfeld et al. , 1981, Mercer and Beart, 1997, Mercer et al. , 2000) and the anxiogenic properties have been shown to be regulated mainly through CCK2-R. Thus, Fekete and co-workers reported that anxiety and fear were aroused by means of injecting CCK-8 into the central nucleus of amygdala in rats (Fekete et al. , 1981), an effect that was found to be blocked by CCK2-R antagonists (Rotzinger and Vaccarino, 2003). CCK1-R on the other hand, seems rather to be involved in anxiolysis (Cohen et al. , 2004). Pre-pro-CCK is cleaved into smaller biologically active units that can act as neuromodulatory peptides. For instance, CCK-4 and CCK-8 have been found to enhance anxiety- and panic-like behaviour in different animal models (Rex et al. , 1997, Wunderlich et al. , 2002). Furthermore, recent studies in humans have shown that CCK-4induced panic is correlated with increased glutamate in the anterior cingulate cortex (aCctx) (Zwanzger et al. , 2013).

CCK fluctuates during the estrous cycle in several brain regions (Frankfurt et al. , 1986, Hilke 
et al. , 2007) and the concentration of CCK-like immunoreactivity (LI) was found to be lowest during the pro-estrous phase, when the concentration of estrogen in plasma was at its highest level. Limited studies have shown that both CCK and its receptors are sensitive to estrogen (Micevych et al. , 1996, Micevych et al. , 1997). However, there are still a lot of questions yet to be answered. A deeper understanding of how sex-hormones can affect the CCK system may open new possibilities in our understanding of neuropsychiatric disorders such as anxiety and depression in females.

The classical mechanism of estrogen activation is mediated through the nuclear transcription factor receptors, estrogen receptor (ER)- $\alpha$ (Jensen, 1996) and/or ER $\beta$ (Kuiper et al. , 1996) and the subsequent regulation of gene expression. However, estrogen also exerts acute effects on synaptic physiology that occur too rapidly to involve changes in gene expression (Kelly and Levin, 2001, Wong and Moss, 1992). These rapid effects have been attributed to extranuclear ER $\alpha / E R \beta$ or to novel ERs yet to be characterized. Some studies have reported extra nuclear immunoreactivity for $\mathrm{ER} \alpha$ (Milner et al. , 2001) and ER $\beta$ (Mitra et al. , 2003) in dendrites, axons, and glia in the rat brain, e.g. in the hippocampus and hypothalamus. Interestingly, a high degree of extra nuclear ERs in the hippocampus has been found to be co-localized with neuropeptides such as neuropeptide Y (Hart et al. , 2007). In addition, we have previously reported acute effects on neuropeptide levels and release (NPY and galanin) in parts of the limbic system already within hours after a single injection of 17 $\beta$-estradiol (Hilke et al. , 2009, Hilke et al. , 2005). Taken together, these studies indicate that estrogen can exert both rapid and long-term effects on different neuropeptide systems involved in mood-related behaviour.

With this background we hypothesized that fluctuations of CCK during the estrous cycle might be regulated directly or indirectly by estradiol, or the other way around. Our aim was therefore to study if depletion of estrogen by means of ovariectomy (OVX) and replacement with 17ßestradiol could influence CCK-LI concentration in brain regions involved in mood and reward- 
related behaviour such as aCctx, amygdala (Amy), hippocampus/dentate gyrus (DG) and nucleus accumbens (NAc). Another question addressed was if these changes in CCK are associated with an influence on anxiety-like behaviour. We believe that our results support our hypothesis that estrogen influences the CCK peptide system in brain regions important for emotional processes and that change in CCK-LI concentration was associated with a decrease in anxiety-like behaviour. Acute effects on CCK-LI concentration were measured by means of radioimmunoassay and anxiety-like behaviour was tested using the elevated plus maze (EPM).

\section{Materials and methods}

\subsection{Animals and surgery}

\subsubsection{Housing}

Female Sprague Dawley rats ( $=$ 80, 234 \pm 32 gram, Universal, Stockholm, Sweden) were kept at the Animal Unit CBR5 of Linköping University Hospital. The animals were housed two and two in each cage at constant room temperature $\left(20^{\circ} \mathrm{C}\right)$, with chow and water during a $12 \mathrm{hr}$ dark and $12 \mathrm{hr}$ light cycle (light on at 6.00 p.m.). The rats were habituated for two weeks prior to surgery. The study and its experimental protocol were designed according to the guidelines of the local ethics committee on animal research in Linköping and according to EU guidelines and were approved by the committee.

\subsubsection{Ovariectomy and sham operation}

OVX and sham-operation were performed in anaesthetized animals (0.5-1.5\% isofluorane, Sigma-Aldrich, St. Louis, MO, USA) and accomplished by the dorsal route. The ovaries were removed from the abdominal cavity and the junction between the fallopian tube and the uterine horn was sutured. A similar procedure was performed in the sham-operated animals except that the uterine horn was not sutured and the ovaries were carefully put back in the abdominal cavity within the perigonadal fat pad without touching them directly. All animals were left for a one week washout period after surgery. No animals were excluded. Groups: A total of 80 rats were used in two separate experiments; 40 rats for studies of CCK-LI concentration in the brain and 
40 rats for studies of anxiety-like behaviour by means of elevated plus maze (body weight at decapitation and EPM 250 \pm 53 gram). In both experiments 40 rats were randomized into 4 groups (n=10 in each group), 1) sham-operated rats with intact ovaries receiving a single dose of $30 \mu \mathrm{L}$ sesame oil (Sigma-Aldrich) 2) sham-operated rats with intact ovaries receiving a single dose of $10 \mu \mathrm{g} 17 \beta$-estradiol in $30 \mu \mathrm{L}$ sesame oil (Sigma-Aldrich), 3) ovariectomized (ovx) control rats, ,4) ovx rats receiving a single dose of $10 \mu \mathrm{g} 17 \beta$-estradiol in $30 \mu \mathrm{L}$ sesame oil (Sigma-Aldrich). The injections of estradiol or sesame oil in all rats were performed exactly after a one week washout-period to eliminate endogenous estrogen production form the ovaries.

\subsubsection{Tissue extraction of CCK}

All animals were decapitated $2 \mathrm{~h}$ after administration of $17 \beta$-estradiol and/or sesame oil respectively (8.00-10.00 A.M.). Punch biopsies were collected from aCctx, Amy, DG and NAc and stored at $-80^{\circ} \mathrm{C}$ until analysis. Extraction of the punch biopsies was performed according to the following protocol: $0.5 \mathrm{~mL}$ MQ water was heated at $100^{\circ} \mathrm{C}$ using a heating-block (Grant, Royston, Cambridge, England) and added into the polypropylene vials with the biopsies for 10 min. The tissues were homogenized and centrifuged at $1500 \mathrm{x} \mathrm{g}, 4^{\circ} \mathrm{C}$ for $10 \mathrm{~min}$. After collecting the supernatants, a second extraction was performed with $0.5 \mathrm{~mL}$ of $0.1 \mathrm{M} \mathrm{NaOH}$. In accordance with Ryder and co-workers (data not shown), we found that this extraction procedure yielded higher concentrations of CCK compared to the commonly used weak acid 0.1 HAc (Ryder et al. , 1981). The supernatants were pooled together, lyophilized and stored at $-80^{\circ} \mathrm{C}$.

\subsection{CCK-LI concentration}

The concentration of CCK-LI was measured using a commercial radioimmunoassay (EURIA kit, Euro Diagnostica, Malmö, Sweden). A calibration-curve was made from serial dilutions of $1 \mathrm{~mL}$ CCK-8 standard (50 pmoL/L) in $1 \mathrm{~mL}$ assay buffer (0.05M phosphate buffer, $\mathrm{pH}$ 7.4, containing $0.25 \%$ human serum albumin and $0.02 \%$ merthiolate) with the final concentrations of $0.78,1.56,3.12,6.25,12.5$ and 25 pmoL/L. The concentrations of CCK-LI were measured 
using a rabbit antiserum (anti-CCK-8) diluted in $5.0 \mathrm{~mL}$ 0.5M phosphate buffer, $\mathrm{pH}$ 7.4, with $2.5 \%$ human serum albumin and $0.5 \%$ ProColin with a very low cross-reactivity to gastrin (Rehfeld, 1998).

The lyophilized samples were reconstituted in $1.0 \mathrm{~mL}$ assay buffer $(0.05 \mathrm{M}$ phosphate buffer, pH 7.4 containing $0.25 \%$ human serum albumin and $0.02 \%$ merthiolate) and $200 \mu \mathrm{L}$ of each sample. -Controls and standard were mixed with $500 \mu \mathrm{L}$ anti-CCK-8 and incubated for 50h at $6^{\circ} \mathrm{C}$. HPLC-purified, ${ }^{125}$ I cholecystokinin 26-33 sulphate (produced by the Bolton and Hunter method), was used as a radioligand (500 $\mu \mathrm{L}, 6472 \mathrm{cpm})$ and incubated for $100 \mathrm{~h}$ at $6^{\circ} \mathrm{C}$. Finally, $100 \mu \mathrm{L}$ double antibody solid phase (Anti-rabbit-lg coupled to cellulose particles) was added, mixed and incubated for $60 \mathrm{~min}$ at $6^{\circ} \mathrm{C}$ and centrifuged at $1700 \mathrm{x}$ g for $15 \mathrm{~min}$ at $4^{\circ} \mathrm{C}$. The supernatant was discarded by aspiration and the radioactivity in the pellets containing the bound fraction of samples and calibrators was measured with a gamma counter (Perkin Elmer 2470, Massachusetts, USA).

\subsection{Elevated plus maze}

Forty rats were randomized into four groups as described above ( $\mathrm{n}=10$ in each group). The rats were allowed to habituate for one hour in the experimental room before start and then subjected to behavioural tests on the EPM (8.00-10.00 P.M.) - 2 and $24 \mathrm{hr}$ following a single dose of $30 \mu \mathrm{L}$ sesame oil alone or $10 \mu \mathrm{g} 17 \beta$-estradiol in $30 \mu \mathrm{L}$ sesame oil.

EPM is a validated animal model of anxiety that is based on the natural aversion in rodents to height and open spaces (Pellow et al. , 1985). Each rat was placed on the center platform facing an open arm. Behaviours scored were the number of open and closed arm entries and time spent on the various sections of the maze for five min. Arm entries were defined as entry of all four paws into the arm. A camera was mounted above the apparatus which allowed the observation of the animal's behaviour and scoring. The time spent on open arms and the 
number of entries on the open arms was expressed as a percentage of the total number of arm entries and test duration, respectively.

\subsection{Statistical analysis}

Standard error of the mean (SEM) was used to represent the central tendency and variation of the CCK-LI concentration in the figures. Two-way analyses of variance tests (ANOVAs) were employed to determine the overall effects (GraphPad Prism, version 5.4, 2010). A p-value of $<0.05$ was considered significant.

\section{Results}

\subsection{Effects of 17ß-estradiol on CCK-LI concentration}

The effect on CCK-LI concentration after a single injection of $17 \beta$-estradiol/sesame oil or sesame oil alone was studied in sham operated and ovx rats $2 \mathrm{~h}$ after administration. We found no effect of ovariectomy alone in NAc, Amy or DG comparing sham control and ovx control rats (Figure 1,3,4) but an increase in CCK-LI concentration in ovx rats in $\operatorname{Cctx}(\mathrm{p}<0.001$, Figure 2).

In ovx rats, we found a decrease in CCK-LI concentration in NAc, $2 \mathrm{~h}$ after administration of $17 \beta$-estradiol ( $p<0.01$, Figure 1 ) and a tendency to a decrease in aCctx (Figure 2) and Amy (Figure 3), compared to ovx control animals. In sham-operated rats with intact ovaries, administration of 17ß-estradiol did not induce a decrease in CCK-LI but instead showed a trend towards an increase (not significant) compared to sham controls. Moreover, the sham control rats and those administered with $17 \beta$-estradiol showed significantly higher levels of CCK-LI in NAc compared to ovx rats administered with $17 \beta$-estradiol $(\mathrm{p}<0.01$ and $\mathrm{p}<0.001$, respectively). In DG (hippocampus) 17 $\beta$-estradiol administration to ovx rats did not induce any effect on CCK-LI concentration (Figure 4). However, administration of $17 \beta$-estradiol in sham-operated rats induced an increase in CCK-LI when compared to sham controls.

In Amy, the levels of CCK-LI concentration were significantly higher in sham operated rats 
administered with $17 \beta$-estradiol, compared to both ovx control rats and ovx rats administered with $17 \beta$-estradiol (Figure 3, $\mathrm{p}<0.05$ and $\mathrm{p}<0.001$ respectively).

In summary, the effects of acute administration of $17 \beta$-estradiol on CCK-LI concentration when comparing the groups of sham-operated rats with intact ovaries and ovx rats without ovaries are dichotomous.

\subsection{Effects of $17 \beta$-estradiol on anxiety-like behaviour}

Animals were subjected to behavioural tests on the EPM for $2 \mathrm{~h}$ and $24 \mathrm{~h}$ following a single dose of sesame oil alone or $17 \beta$-estradiol in sesame oil to ovx and sham-operated rats. Administration of $17 \beta$-estradiol to ovx animals compared to ovx control rats was found to reduce anxiety-like behaviour $2 \mathrm{~h}$ after administration $(\mathrm{p}<0.05$, Figure 5$)$. This decreased anxiety-like behaviour was however no longer observed when tested 24h later, although the tendency was the same. However, in sham-operated rats administered with $17 \beta$-estradiol anxiety-like behaviour was unaffected after $2 \mathrm{~h}$ but after $24 \mathrm{~h}$ profoundly decreased compared to sham control rats, $(p<0.05$, Figure 5). There was no difference in the number of total entries of closed arms (used as a measure of possible effects on locomotion).

\section{Discussion}

This study supports our hypothesis that estradiol influences the CCK peptide system in brain regions that are important for emotional processes and that estradiol is probably involved in the previously reported fluctuations during a normal estrous cycle. For instance, in ovx animals $17 \beta$-estradiol was found to induce a significant decrease in CCK-LI concentration in NAc and tends to cause decreases in Cctx and Amy, changes not seen in the ovx control rats (although not reaching significance). We found no effect on CCK-LI concentration in hippocampus (DG) in ovx rats administered with $17 \beta$-estradiol. This lack of $17 \beta$-estradiolinduced effect on CCK-LI in DG is in agreement with a study by Nakamura and McEwen, using the same dose as in the present study. They studied CCK mRNA and used a different 
time point (24hr) and found no effect on CCK transcript after 17ß-estradiol administration (Nakamura and McEwen, 2005). A surprising observation in the present study was that $17 \beta$ estradiol did not seem to have the same influence on CCK in sham-operated rats with intact ovaries as in ovx administered rats. Thus, a single shot of $17 \beta$-estradiol to sham-operated animals was found to induce an increase in CKK-LI concentration in DG compared to sham control rats and a small tendency for an increase in aCctx, NAc and Amy. These findings are in opposition to results observed from 17ß-estradiol administration on ovx rats. A possible explanation could be that there are other steroid-induced interactions with the CCK system in the sham-operated rats with intact production of other gonadal sex-hormones i.e.

progesterone. However, this needs to be further investigated.

Researchers reported as early as 1986 that fluctuations of CCK levels occur during a normal estrous cycle in a number of regions in the brain as mentioned before. Thus, in an early report by Frankfurt and co-workers (Frankfurt et al., 1986), CCK-LI concentration was found to be reduced during pro-estrous in the amygdala when levels of estrogen are high. A trend towards a decrease in CCK-LI was also observed in the hippocampus in the same study, but did not reach significance. A similar and significant reduction of CCK-LI in the hippocampus as well as in other extra-hypothalamic areas (e.g. cortex cingulate, striatum) (Hilke et al., 2007) supports the original finding. Decreased tissue-concentration of CCK was observed during the pro-estrous phase compared to di-estrous and estrous in normal cycling rats. The amygdala was however not investigated in this latter study. Acute effects of estrogen on CCK-LI concentration (within hours) that are linked to anxiety-like behaviour have to our knowledge not been studied elsewhere. Nevertheless, a study by Geary and co-workers (Geary, 2001) showed, again using the same dose, that estrogen combined with injections of CCK-8, induces increases of c-FOS in the central amygdala following both acute and chronic administration. This indicates that estrogen can rapidly influence and activate cells in the Amy that are 
dependent on CCK. Nonetheless, in the present study of Amy, we only found tendencies of reduced CCK-LI $2 \mathrm{~h}$ after administration with estradiol to ovx rats.

Here we also report, that the observed $17 \beta$-estradiol-induced decrease in CCK-LI concentration in ovx rats in the first experiment was accompanied by anxiolytic-like behaviour in the second experiment. Thus, replacement with $17 \beta$-estradiol reduced anxietylike behaviour in the EPM as soon as $2 \mathrm{~h}$ after administration. This effect was no longer observed when the rats were tested a second time, 24h later, although we found a small trend towards a decrease. However, the possible correlation between CCK-LI concentration and anxiety-like behaviour is not causal until it's proven and should be interpreted with caution. Especially since the results were obtained from two different experiments. In any case, our data indicate that $17 \beta$-estradiol can rapidly alter anxiety-like behaviour and there is a possibility that this alteration is related to changes in different parts of the CCK-system. This interesting correlation need to be studied in more detail. Studies of estrogen replacement and effects of OVX itself on anxiolytic and anxiogenic behaviour have previously been reported. Unfortunately, these studies have demonstrated contradictory results that are difficult to interpret. The apparent contradictions may be due in part to differences in the models used for different studies, and in differences in dose and time-frames in the behavioural studies (Lagunas et al. , 2010).

The reason why we studied the rapid effects of estradiol on CCK-LI concentration on anxietylike behaviour is based on earlier interest in the acute effects of estrogen on several other neuropeptide levels and release that are known to be involved in regulating mood-related behaviour. One example is provided by the rapid effects of estrogen on galanin release in hippocampus (DG) within hours after a single injection of $17 \beta$-estradiol to ovx rats as monitored by microdialysis (Hilke et al., 2005). Our main and increasing interest in a possible regulation of sex-hormones particularly on the CCK system is based on the potential for 
applying results to understanding several important issues. One of them is that severe anxiety such as panic disorders are more prevalent in females and CCK is known to be a key-player in panic disorders in humans. The involvement of CCK in panic disorders was in fact originally described in humans. Indeed, intravenous administration of CCK-4 was found to induce panic attacks in both healthy volunteers and in patients suffering from panic disorders (Bradwejn et al. , 1990, Zwanzger et al. , 2012) and sex-differences have been found in these effects which makes them even more interesting. Moreover, of the two types of CCK receptors identified, CCK2-R is most abundant in the brain and also the receptor mainly thought to induce the observed anxiogenic effects. Anxiolytic properties of the two tested antagonists L-365,260 and CI-988 have been observed in animal models. However, although these antagonists were promising, unfortunately they failed to have positive effects on clinical symptoms in patients with panic disorders (Kramer et al. , 1995).

The most interesting finding in the present study was the effects of $17 \beta$-estradiol on CCK in NAc. Thus, the greatest effect on CCK-LI concentration observed in the present study was in the NAc of ovx animals administered with $17 \beta$-estradiol. This indicates a possible interaction with dopamine. Indeed, Hökfelt and co-workers were pioneers in showing anatomical evidence of a pathway with CCK-positive fibers projecting from the ventral tegmental area to NAc, as well as in reporting the CCK cortico-striatal pathway (Hökfelt et al., 1980).

Moreover, CCK has also been found to influence dopamine release in NAc. This is interesting in the light of our data, since the dopamine system as well as addictive behaviour exhibits pronounced sex-differences (Becker, 1999).

This study was also designed to investigate rapid behavioural influences of estradiol that might be associated with changes in CCK levels in the female brain. Systemic injections of CCK and analogues in both animals and humans have earlier been associated with a variety of behavioural alternations such as increased anxiety and panic attacks. Since sex-differences 
have been found in the CCK system in the rat brain and since sex-hormones have been implicated in mood-related behaviour and cognitive functions, a deeper understanding of how sex-hormones can affect the CCK system would help to increase our understanding of neuropsychiatric disorders more common in females.

In summary, these data reveal that estrogen-induced decreased anxiety-like behaviour could possibly be correlated with the changes in CCK-LI concentration observed in limbic regions of the female rat brain. A future perspective would be to study estrogen-induced release of CCK e.g. in the limbic system and relationships with different behavioural outcomes. In addition, it would be interesting to investigate if these effects can be observed in mice, which would provide different transgenic animal models.

\section{Acknowledgements}

This study was supported by grants from the County Council Östergötland, Sweden. We thank Linda Gutborn Hansen and Maria Johansson for excellent technical assistance and Lawrence Lundgren for English editing (Right English - Independent Translation and Language Review Service, Linköping, Sweden).

\section{Abbreviations}

Cctx; cingulate cortex, Amy; amygdala, CCK; Cholecystokinin, CCK-LI; cholecystokininlike immunoreactivity, CCK1-R; cholecystokinin receptor 1, CCK2-R; cholecystokinin receptor 2, DG; dentate gyrus, EPM; elevated plus maze, ER; estrogen receptor, h; hours, NAc; nucleus accumbens, ovx; ovariectomized, OVX; ovariectomy. 


\section{References}

Becker JB. Gender differences in dopaminergic function in striatum and nucleus accumbens. Pharmacology, biochemistry, and behavior. 1999;64:803-12.

Beinfeld MC, Meyer DK, Eskay RL, Jensen RT, Brownstein MJ. The distribution of cholecystokinin immunoreactivity in the central nervous system of the rat as determined by radioimmunoassay. Brain Res. 1981;212:51-7.

Bradwejn J, Koszycki D, Meterissian G. Cholecystokinin-tetrapeptide induces panic attacks in patients with panic disorder. Canadian journal of psychiatry Revue canadienne de psychiatrie. 1990;35:83-5.

Cohen H, Kaplan Z, Matar MA, Buriakovsky I, Bourin M, Kotler M. Different pathways mediated by CCK1 and CCK2 receptors: effect of intraperitonal mrna antisense oligodeoxynucleotides to cholecystokinin on anxiety-like and learning behaviors in rats. Depression and anxiety. 2004;20:139-52.

Fekete M, Szabo A, Balazs M, Penke B, Telegdy G. Effects of intraventricular administration of cholecystokinin octapeptide sulfate ester and unsulfated cholecystokinin octapeptide on active avoidance and conditioned feeding behaviour of rats. Acta Physiol Acad Sci Hung. 1981;58:39-45.

Frankfurt M, Siegel RA, Sim I, Wuttke W. Estrous cycle variations in cholecystokinin and substance P concentrations in discrete areas of the rat brain. Neuroendocrinology. 1986;42:226-31.

Geary N. Estradiol, CCK and satiation. Peptides. 2001;22:1251-63.

Hart SA, Snyder MA, Smejkalova T, Woolley CS. Estrogen mobilizes a subset of estrogen receptor-alpha-immunoreactive vesicles in inhibitory presynaptic boutons in hippocampal CA1. J Neurosci. 2007;27:2102-11.

Hilke S, Holm L, Åman K, Hökfelt T, Theodorsson E. Rapid change of neuropeptide Y levels and gene-expression in the brain of ovariectomized mice after administration of 17beta- 
estradiol. Neuropeptides. 2009;43:327-32.

Hilke S, Hökfelt T, Darwish M, Theodorsson E. Cholecystokinin levels in the rat brain during the estrous cycle. Brain research. 2007;1144:70-3.

Hilke S, Theodorsson A, Fetissov S, Åman K, Holm L, Hökfelt T, et al. Estrogen induces a rapid increase in galanin levels in female rat hippocampal formation--possibly a nongenomic/indirect effect. Eur J Neurosci. 2005;21:2089-99.

Hökfelt T, Rehfeld JF, Skirboll L, Ivemark B, Goldstein M, Markey K. Evidence for coexistence of dopamine and CCK in meso-limbic neurones. Nature. 1980;285:476-8.

Jensen EV. Steroid hormones, receptors, and antagonists. Annals of the New York Academy of Sciences. 1996;784:1-17.

Karkanias CD, Block GA, Reines S, Bradwejn J. Neurobiology of panic disorder. The American journal of psychiatry. 1989;146:1357.

Kelly MJ, Levin ER. Rapid actions of plasma membrane estrogen receptors. Trends in endocrinology and metabolism: TEM. 2001;12:152-6.

Kramer MS, Cutler NR, Ballenger JC, Patterson WM, Mendels J, Chenault A, et al. A placebo-controlled trial of L-365,260, a CCKB antagonist, in panic disorder. Biological psychiatry. 1995;37:462-6.

Kuiper GG, Enmark E, Pelto-Huikko M, Nilsson S, Gustafsson JA. Cloning of a novel receptor expressed in rat prostate and ovary. Proceedings of the National Academy of Sciences of the United States of America. 1996;93:5925-30.

Lagunas N, Calmarza-Font I, Diz-Chaves Y, Garcia-Segura LM. Long-term ovariectomy enhances anxiety and depressive-like behaviors in mice submitted to chronic unpredictable stress. Horm Behav. 2010;58:786-91.

Larsson LI, Rehfeld JF. Localization and molecular heterogeneity of cholecystokinin in the central and peripheral nervous system. Brain research. 1979;165:201-18. 
Lu L, Zhang B, Liu Z, Zhang Z. Reactivation of cocaine conditioned place preference induced by stress is reversed by cholecystokinin-B receptors antagonist in rats. Brain research. 2002;954:132-40.

Mercer LD, Beart PM. Histochemistry in rat brain and spinal cord with an antibody directed at the cholecystokininA receptor. Neurosci Lett. 1997;225:97-100.

Mercer LD, Le VQ, Nunan J, Jones NM, Beart PM. Direct visualization of cholecystokinin subtype2 receptors in rat central nervous system using anti-peptide antibodies. Neurosci Lett. 2000;293:167-70.

Micevych P, Eckersell CB, Holland K, Smith A. Induction of CCK mRNA levels in the limbic-hypothalamic circuit: time course and site-specific effects of estrogen. J Neurobiol. 1996;30:465-79.

Micevych PE, Eckersell CB, Brecha N, Holland KL. Estrogen modulation of opioid and cholecystokinin systems in the limbic-hypothalamic circuit. Brain Res Bull. 1997;44:335-43.

Micevych PE, Park SS, Akesson TR, Elde R. Distribution of cholecystokininimmunoreactive cell bodies in the male and female rat: I. Hypothalamus. J Comp Neurol. 1987;255:124-36.

Milner TA, McEwen BS, Hayashi S, Li CJ, Reagan LP, Alves SE. Ultrastructural evidence that hippocampal alpha estrogen receptors are located at extranuclear sites. J Comp Neurol. 2001;429:355-71.

Mitchell JM, Bergren LJ, Chen KS, Fields HL. Cholecystokinin is necessary for the expression of morphine conditioned place preference. Pharmacology, biochemistry, and behaviour. 2006;85:787-95.

Mitra SW, Hoskin E, Yudkovitz J, Pear L, Wilkinson HA, Hayashi S, et al. Immunolocalization of estrogen receptor beta in the mouse brain: comparison with estrogen receptor alpha. Endocrinology. 2003;144:2055-67. 
Nakamura NH, McEwen BS. Changes in interneuronal phenotypes regulated by estradiol in the adult rat hippocampus: a potential role for neuropeptide Y. Neuroscience. 2005;136:357-69.

Pellow S, Chopin P, File SE, Briley M. Validation of open:closed arm entries in an elevated plus-maze as a measure of anxiety in the rat. J Neurosci Methods. 1985;14:149-67.

Pommier B, Beslot F, Simon A, Pophillat M, Matsui T, Dauge V, et al. Deletion of CCK2 receptor in mice results in an upregulation of the endogenous opioid system. The Journal of neuroscience : the official journal of the Society for Neuroscience. 2002;22:2005-11.

Rehfeld JF. How to measure cholecystokinin in tissue, plasma and cerebrospinal fluid. Regulatory peptides. 1998;78:31-9.

Rex A, Marsden CA, Fink H. Cortical 5-HT-CCK interactions and anxiety-related behaviour of guinea-pigs: a microdialysis study. Neurosci Lett. 1997;228:79-82.

Rotzinger S, Lovejoy DA, Tan LA. Behavioural effects of neuropeptides in rodent models of depression and anxiety. Peptides. 2010;31:736-56.

Rotzinger S, Vaccarino FJ. Cholecystokinin receptor subtypes: role in the modulation of anxiety-related and reward-related behaviours in animal models. Journal of psychiatry \& neuroscience : JPN. 2003;28:171-81.

Ryder SW, Eng J, Straus E, Yalow RS. Extraction and immunochemical characterization of cholecystokinin-like peptides from pig and rat brain. Proceedings of the National Academy of Sciences of the United States of America. 1981;78:3892-6.

Vanderhaeghen JJ, Lotstra F, De Mey J, Gilles C. Immunohistochemical localization of cholecystokinin- and gastrin-like peptides in the brain and hypophysis of the rat. Proceedings of the National Academy of Sciences of the United States of America. 1980;77:1190-4.

Wong M, Moss RL. Long-term and short-term electrophysiological effects of estrogen on the synaptic properties of hippocampal CA1 neurons. The Journal of neuroscience : the 
official journal of the Society for Neuroscience. 1992;12:3217-25.

Wunderlich GR, Raymond R, DeSousa NJ, Nobrega JN, Vaccarino FJ. Decreased CCK(B) receptor binding in rat amygdala in animals demonstrating greater anxiety-like behaviour. Psychopharmacology (Berl). 2002;164:193-9.

Zwanzger P, Domschke K, Bradwejn J. Neuronal network of panic disorder: the role of the neuropeptide cholecystokinin. Depression and anxiety. 2012;29:762-74.

Zwanzger P, Zavorotnyy M, Gencheva E, Diemer J, Kugel H, Heindel W, et al. Acute shift in glutamate concentrations following experimentally induced panic with cholecystokinin tetrapeptide--a 3T-MRS study in healthy subjects.

Neuropsychopharmacology : official publication of the American College of Neuropsychopharmacology. 2013;38:1648-54 


\section{Figures}

\section{Nucleus Accumbens}

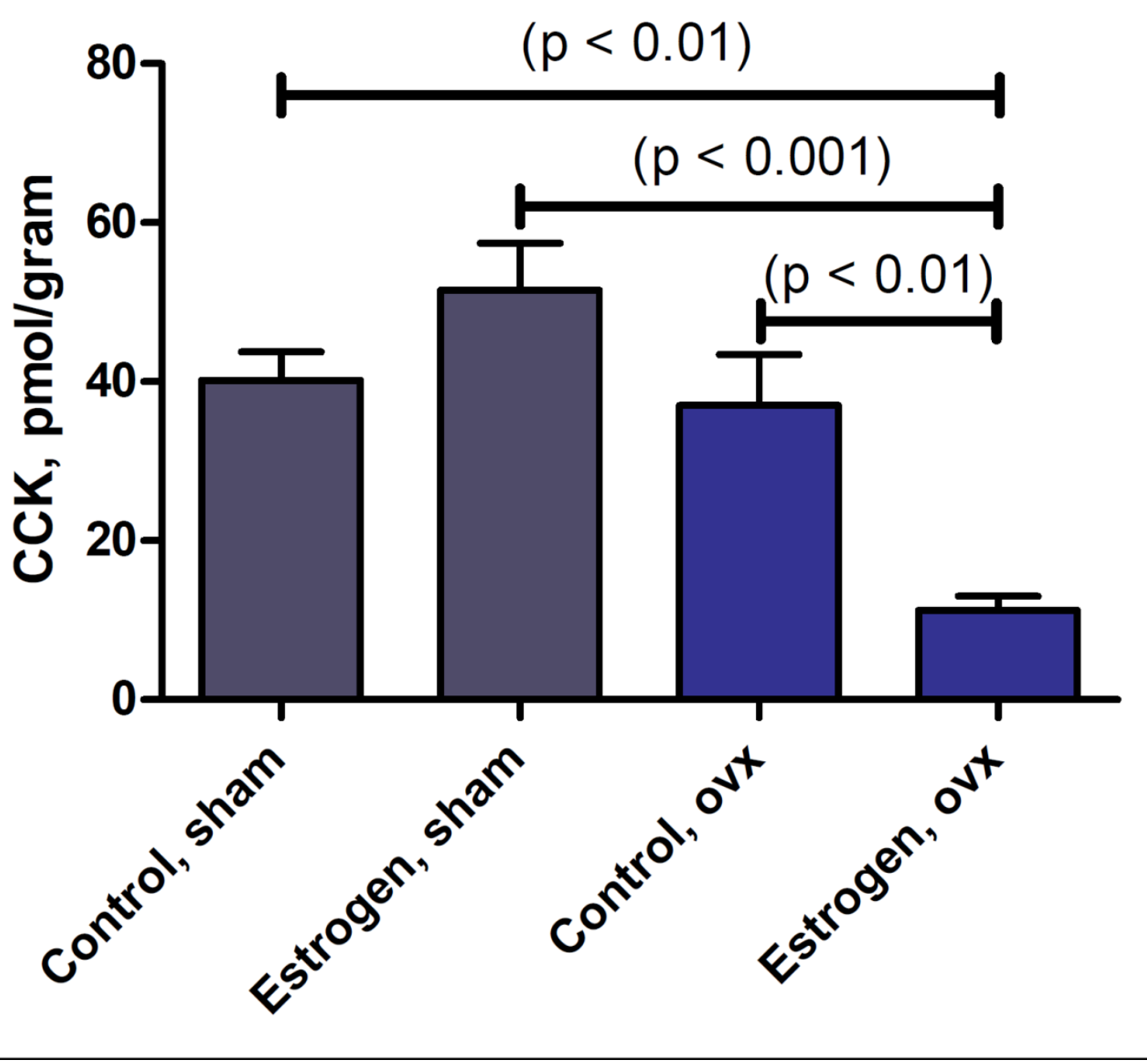

\subsection{Figure 1, Nucleus accumbens}

CCK-LI concentration was greatly reduced in nucleus accumbens two h following a single injection of 17ß-estradiol to ovariectomized animals $(\mathrm{p}<0.01)$. In addition, CCK-LI concentration was decreased after OVX when compared to normal control animals with intact ovaries. 


\section{Cortex Cingulate}

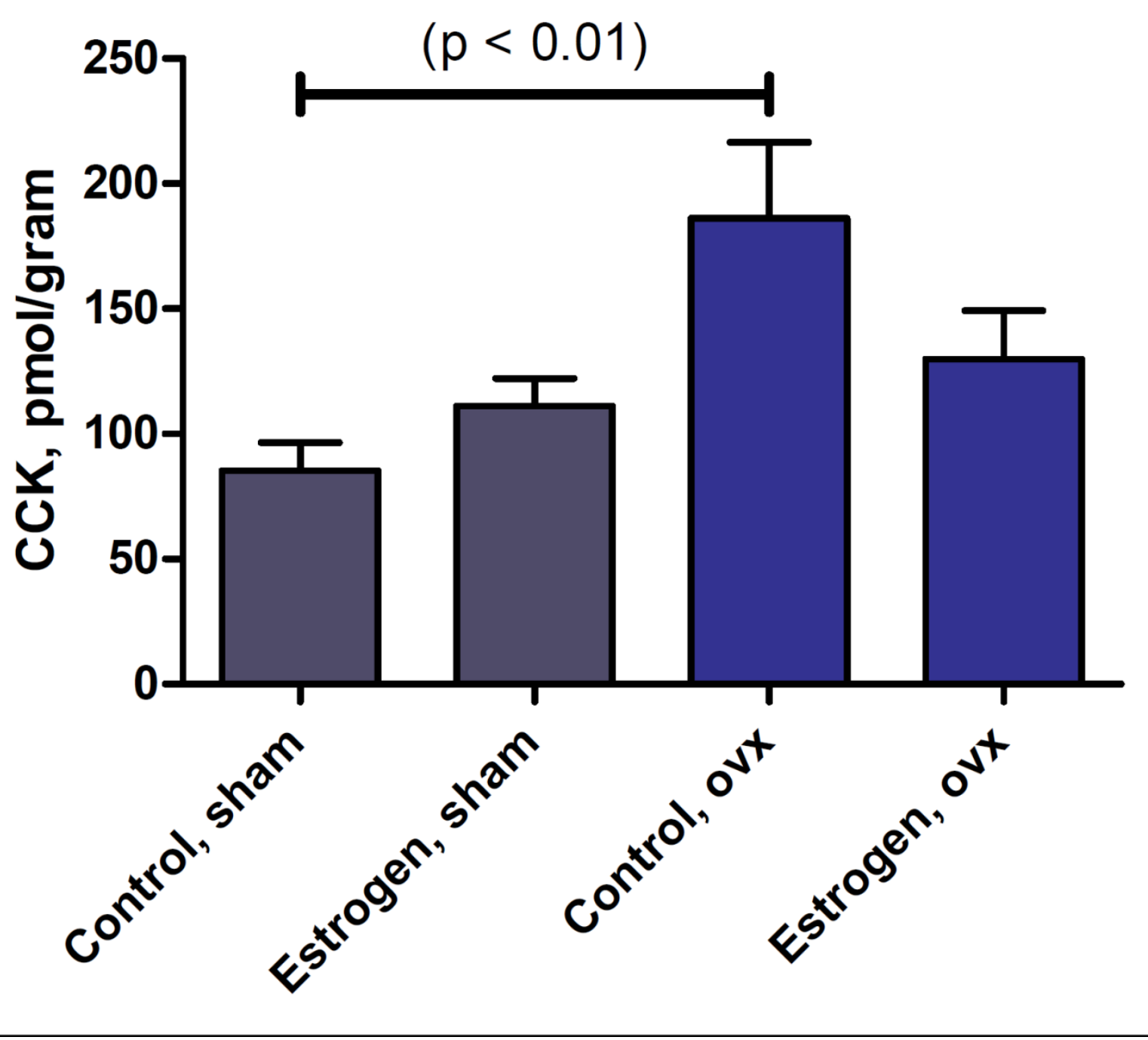

\subsection{Figure 2, Cingulate cortex}

In cortex cingulate, ovariectomy itself was found to induce a profound increase in CCK-LI

concentration compared to normal control animals $(\mathrm{p}<0.01)$ turning back to normal after administration with $17 ß-$-estradiol . 


\section{Amygdala}

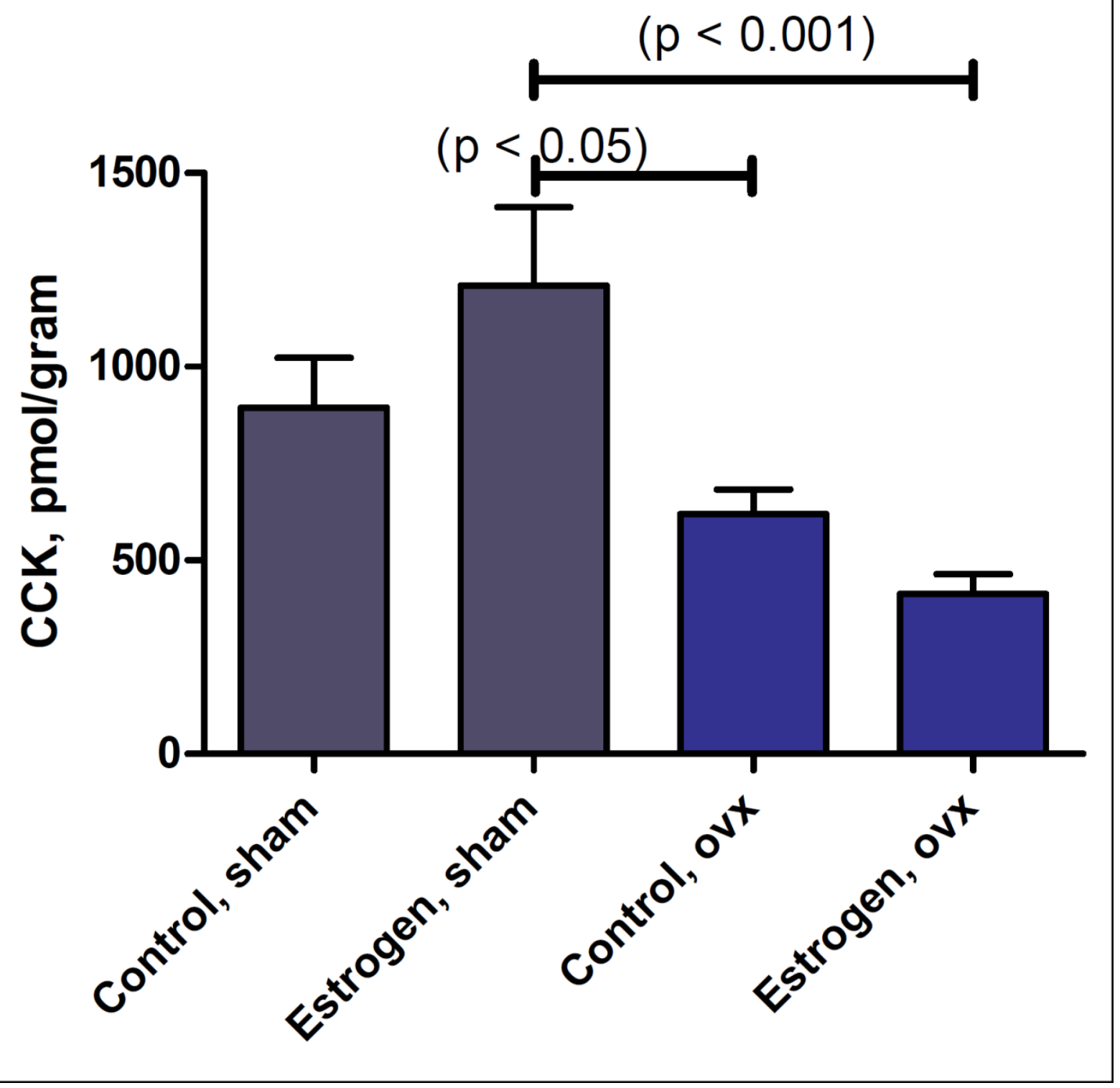

\subsection{Figure 3, Amygdala}

In amygdala, CCK-LI concentration was decreased after ovariectomy $(\mathrm{p}<0.05)$ as well as after replacement with $17 ß$-estradiol $(\mathrm{p}<0.01)$, compared to sham animals administered with $17 ß$ estradiol. Replacement with $17 ß$-estradiol to ovariectomized animals induced a small tendency of decrease in CCK-LI however not significant. 


\section{Hippocampus (dentate gyrus)}

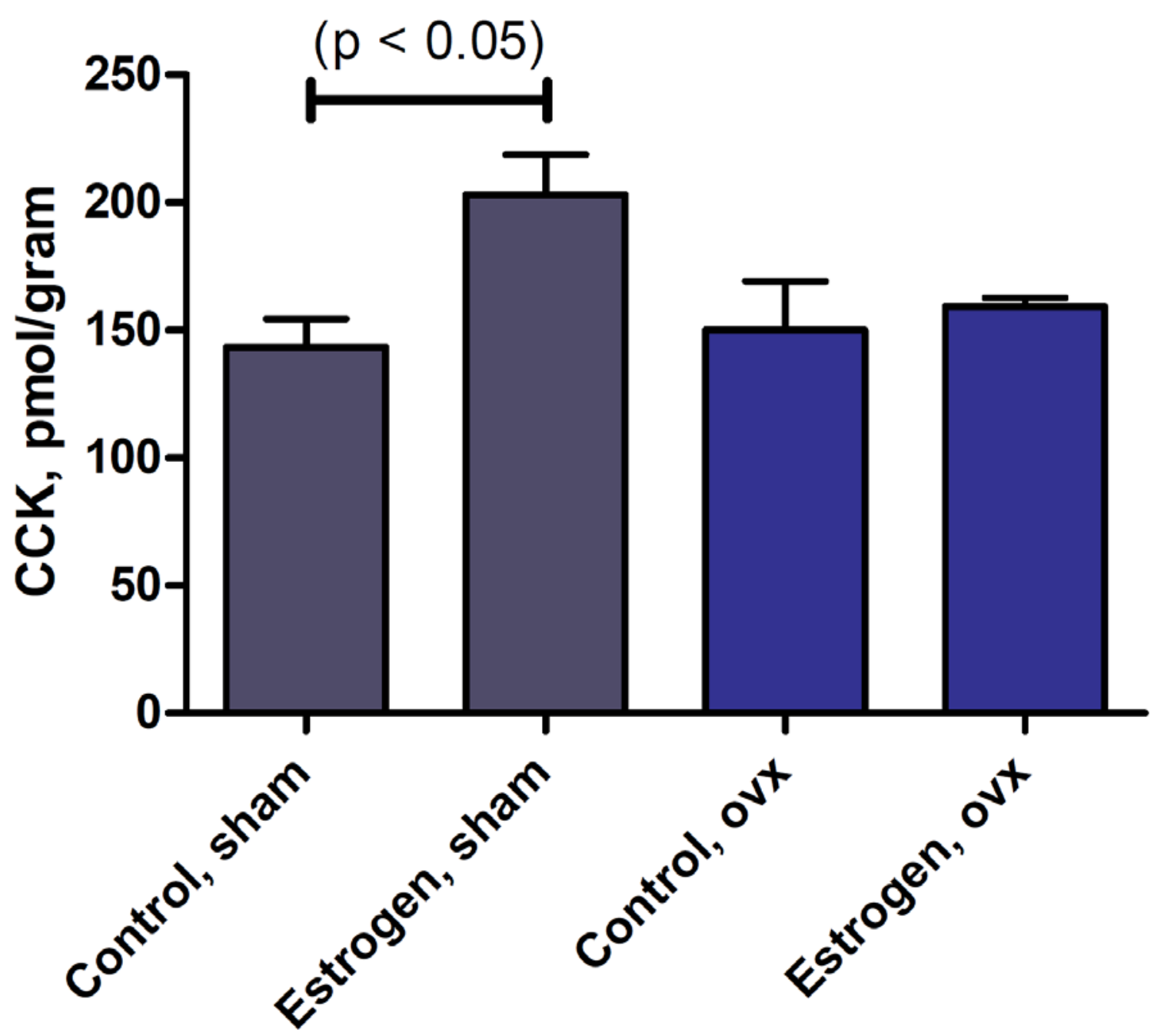

8.4 Figure 4, Hippocampus (dentate gyrus)

In hippocampus (dentate gyrus), 17ß-estradiol administered to normal animals with intact ovaries induced an increase in CCK-LI concentration ( $\mathrm{p}<0.05)$. 


\section{2 hours}

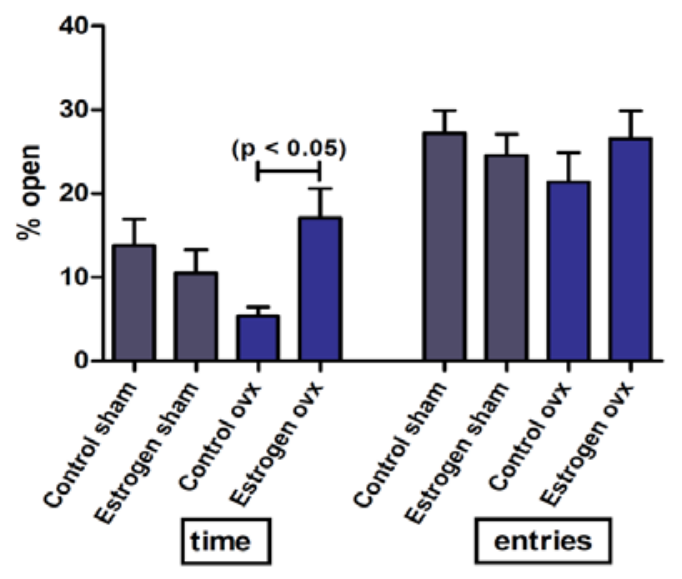

2 hours

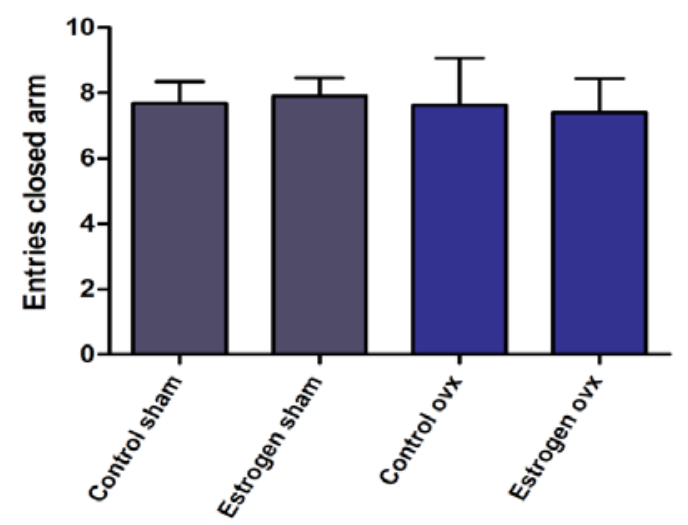

24 hours

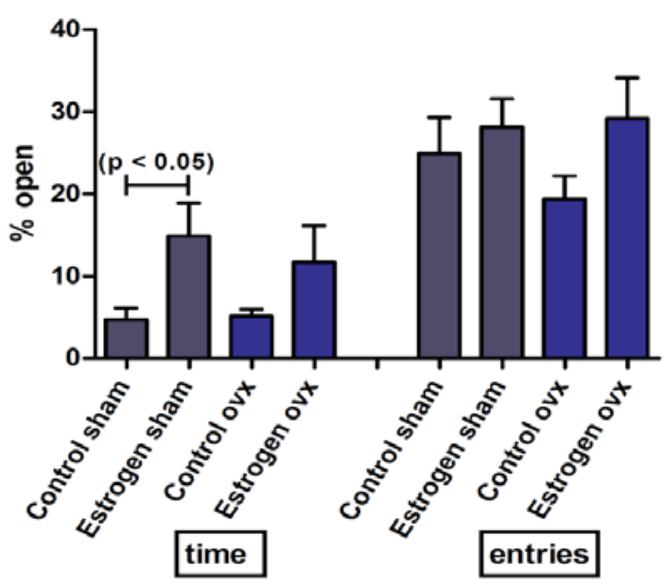

24 hours

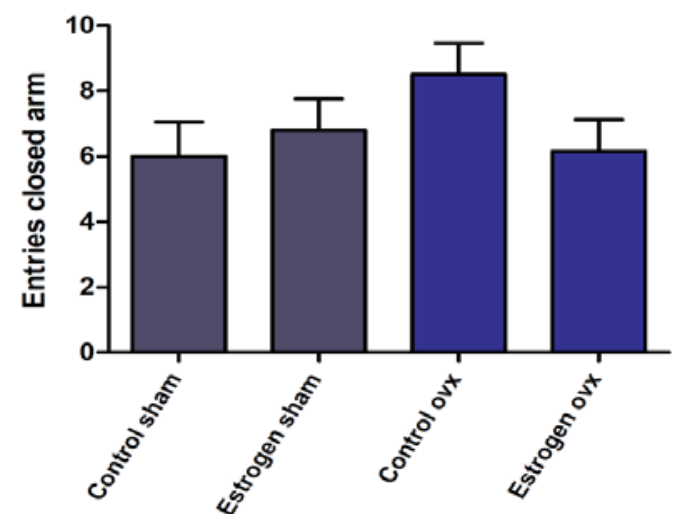

\subsection{Figure 5, Anxiety-like behaviour}

A single injection of $17 ß$-estradiol to ovariectomized animals reduced anxiety-like behaviour

$2 \mathrm{~h}$ after administration $(\mathrm{p}<0.05)$ and to some extent after $24 \mathrm{~h}$ (not significant). In sham animals with intact ovaries given 17ß-estradiol, anxiety-like behaviour was unaffected after 2 $\mathrm{h}$ but greatly reduced after $24 \mathrm{~h}$. Total entries in closed arms was used as a measure of locomotion and not found to be different. 